
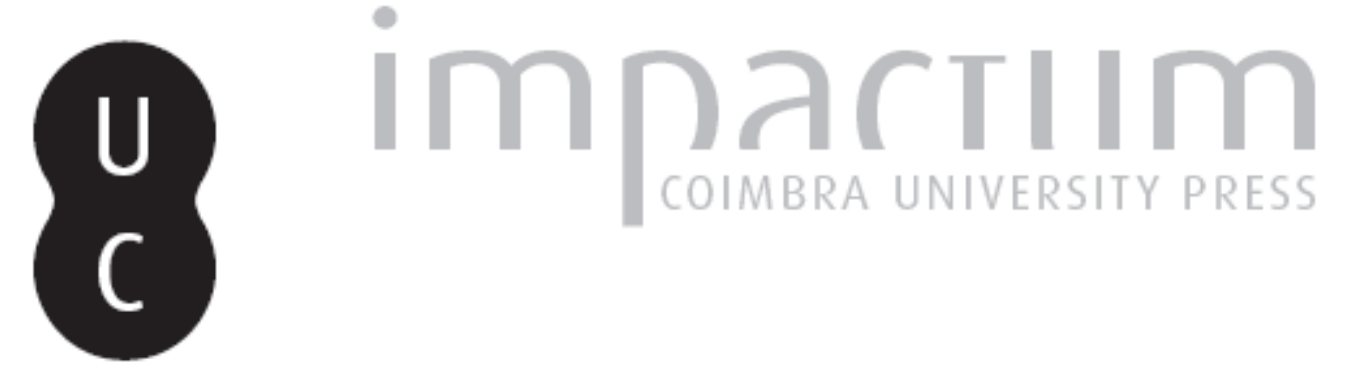

\title{
As partículas gregas (1): gavr
}

\section{Autor(es): $\quad$ Lopes, Rodolfo Pais Nunes}

Publicado por: Associação Portuguesa de Estudos Clássicos; Instituto de Estudos

$\begin{array}{ll}\text { URL } & \text { Clássicos } \\ \text { persistente: } \quad \text { URI:http://hdl.handle.net/10316.2/30467 }\end{array}$

DOI: $\quad$ DOI:http://dx.doi.org/10.14195/0872-2110_49_4

Accessed : $\quad$ 26-Apr-2023 13:14:25

A navegação consulta e descarregamento dos títulos inseridos nas Bibliotecas Digitais UC Digitalis, UC Pombalina e UC Impactum, pressupõem a aceitação plena e sem reservas dos Termos e Condições de Uso destas Bibliotecas Digitais, disponíveis em https://digitalis.uc.pt/pt-pt/termos.

Conforme exposto nos referidos Termos e Condições de Uso, o descarregamento de títulos de acesso restrito requer uma licença válida de autorização devendo o utilizador aceder ao(s) documento(s) a partir de um endereço de IP da instituição detentora da supramencionada licença.

Ao utilizador é apenas permitido o descarregamento para uso pessoal, pelo que o emprego do(s) título(s) descarregado(s) para outro fim, designadamente comercial, carece de autorização do respetivo autor ou editor da obra.

Na medida em que todas as obras da UC Digitalis se encontram protegidas pelo Código do Direito de Autor e Direitos Conexos e demais legislação aplicável, toda a cópia, parcial ou total, deste documento, nos casos em que é legalmente admitida, deverá conter ou fazer-se acompanhar por este aviso.

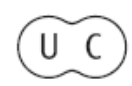




\section{Boletim de}

\section{Estudos Clássicos}

Associação Portuguesa de Estudos Clássicos Instituto de Estudos Clássicos

Coimbra

Junho de 2008 


\section{As Partículas Gregas (1) \\ $\gamma \alpha \dot{\rho}$}

Definir um sistema linguístico e distribuir os seus elementos por classes ou grupos nem sempre é uma tarefa fácil, na medida em que, por vezes, um desses elementos foge a qualquer tipo de caracterização que queiramos adoptar: por vezes, torna-se impossível colocá-lo numa das classes por simplesmente não partilhar de todas as características que definem essa classe e, noutro caso, poderá apresentar características pertencentes a mais do que uma classe, inviabilizando assim a tarefa da compartimentação perfeita e absoluta dos elementos. No caso da Língua Grega, há um conjunto de palavras que se enquadra nestas condições e a que comummente se chama "partículas" que, como veremos, nem cabem em nenhuma classe nem podem por si só formar uma independente.

Diversos estudos foram dedicados a este problema, desde a antiga obra de Hoogeveen ${ }^{1}$, até à mais recente de Denniston ${ }^{2}$, passando por um capítulo de Syntaxe Grecque de Jean Humbert ${ }^{3}$. Ainda assim, a existência destas obras de fundo não invalida um breve estudo sobre as partículas que vise reunir e esclarecer as suas principais dificuldades de entendimento e tradução.

No que diz respeito à definição de "partícula", Denniston prefere uma designação mais filosófica do que linguística: "palavra que exprime um modo de pensamento, tomado quer isoladamente, quer em relação a outro pensamento, ou a um estado emotivo" 4 . Pelo contrário, Humbert inclui esta classe nos elementos de coordenação e atribui-lhe um papel semelhante ao da pontuação moderna ${ }^{5}$. A orientação deste é bem mais adequada do que a daquele, porque, além de se basear em critérios linguísticos, traça um

${ }^{1}$ J. Seager (trad.), Hoogeveen's Greek Particles: Abridged and Translated into English, London, A. J. Valpy, 1829.

2 J. D. Denniston, The Greek Particles, Oxford, Clarendon Press, 1970, $2^{\mathrm{a}}$ ed.

3 J. Humbert, Syntaxe Grecque, Paris, Klincksieck, 1972, $3^{\mathrm{a}}$ ed.

4 J. D. Denniston, op. cit., p. xxxvi.

5 J. Humbert, op. cit., $§ 657$. 
paralelo com as línguas modernas, o que facilita bastante a compreensão do comportamento destas palavras. Se analisarmos expressões portuguesas como "portanto", "ora", "é que", "eis que”, entre outras, verificamos que as dificuldades de definição são as mesmas, pelo que esta aproximação à língua de chegada será bastante útil.

As implicações destas palavras não se limitam apenas ao âmbito da linguística grega nem muito menos podem ser encaradas como um simples pormenor sem importância. Muito pelo contrário, a sua compreensão constitui uma ferramenta importantíssima, quer no ensino, quer na aprendizagem, quer na própria tradução da língua grega; em muitos dos casos, ignorar uma partícula inviabiliza a plena compreensão de um texto, seja qual for a perspectiva: professor, aluno ou tradutor.

\section{A partícula $\gamma a ́ \rho$}

\section{Origem}

É geralmente aceite que esta partícula provém da contracção entre duas outras partículas: $\gamma \epsilon$ e ăp. Ainda assim, existem algumas objecções que podem ser feitas a esta teoria: a forma yápa não se encontra atestada e as

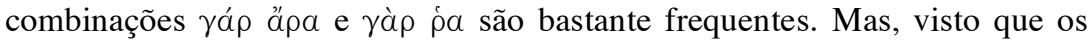
dados são insuficientes e que esta etimologia é atestada por várias obras de referência, entre as quais os dicionários de Liddell and Scott e de Boisacq, é preferível assumir que a origem da partícula é mesmo a contracção entre $\gamma \in \mathrm{e}$ äp.

\section{Usos e sentidos}

De uma maneira geral, a partícula ráp funciona como um elemento de ligação de proposições e está inserida naquela que representa um acrescento da principal, constituindo assim estruturas de subordinação semântica. As

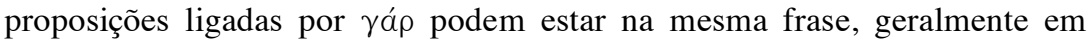
orações diferentes, e mantêm entre si relações de sentido asseguradas pela partícula - subordinação directa. Por outro lado, a ligação pode ser estabelecida entre proposições que se encontrem em orações ou mesmo frases diferentes, funcionando a partícula como um elemento que recupera ou subentende a proposição que já fora referida - subordinação indirecta. 
1. Estruturas de subordinação directa

a) Sentido explicativo/completivo

Assume um carácter explicativo, quando se encontra numa proposição que completa o sentido da principal, acrescentando-lhe uma informação adicional. Com este sentido, traduz-se geralmente por "é que":

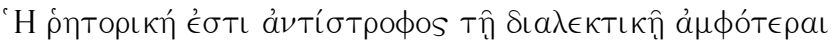

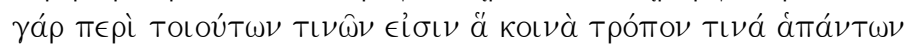

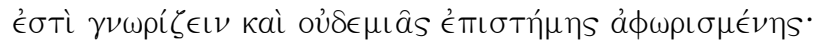

A Retórica é o outro lado da Dialéctica; é que ambas tratam de assuntos respeitantes ao conhecimento comum, não tendo que ver com nenhuma ciência em concreto.

(Arist.Rh.1354a.1-3)

b) Sentido causal

Quando assume este sentido, tem um comportamento semelhante a uma oração subordinada causal. Ainda assim, não se pode falar de uma relação sintáctica, visto que a partícula não é uma conjunção, pois não exige construções-modelo ou regências particulares, como acontece com as estruturas de subordinação sintáctica. Neste caso, deve traduzir-se por "pois", ou mesmo por "porque":

(...) oủsé $\mu \mathrm{\nu}$ ol̈

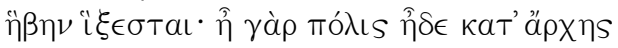

$\pi \epsilon ́ \rho \sigma \epsilon \operatorname{Tal}(. .$.

Mas acho que ele não vai chegar à mocidade, porque ainda antes a cidade será destruída até às ruínas.

(Il. 24.727-729)

c) Justificação de um vocativo

Quando segue um vocativo, estabelece uma ligação entre este caso e a proposição explicativa/completiva, adiantando a justificação pela qual esse vocativo foi usado. Neste caso, é preferível não traduzir a partícula, visto que apenas tem a função de fortalecer a ligação entre os elementos: 


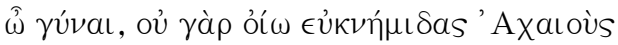

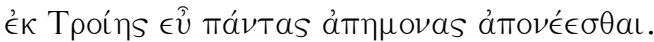

Ó mulher, não creio que os Aqueus de belas cnémides regressem de Tróia sãos e salvos.

$($ Od.18.259-260)

d) Uso parentético

Trata-se do uso parentético quando uma proposição com ráp é incrustada entre duas outras para acrescentar alguma informação adicional, que hoje representamos na escrita entre parênteses ou travessões; daí que alguns editores e tradutores optem por encaixar estas proposições nos critérios gráficos modernos, o que torna bem mais fácil a sua interpretação. Por esta razão, a partícula não se traduz:

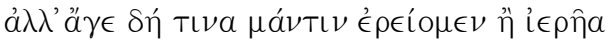

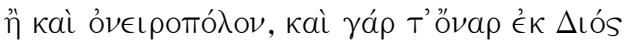

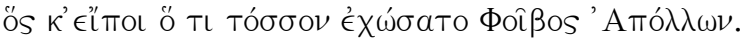

Mas vamos, interroguemos um adivinho, um sacerdote ou até mesmo um intérprete de sonhos - também o sonho tem origem em Zeus -, que há-de dizer por que razão se encolerizou Febo Apolo.

$(I l .1 .62-64)$

2. Estruturas de subordinação indirecta

a) Sentido de assentimento

A partícula pode integrar algumas expressões cristalizadas que denotam uma noção de assentimento. Este sentido é usado preferencialmente em diálogos, quando um interlocutor aprova ou concorda com alguma coisa que fora dita anteriormente:

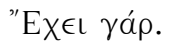

É verdade.

(P1.Phdr.268a.5-6) 


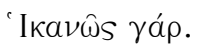

Concordo.

(Pl.R. 502c.4)

b) Interrogações elípticas com sentido confirmativo

Articulada com outras palavras (geralmente advérbios ou pronomes), a

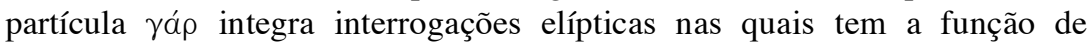
recuperar o que foi referido numa proposição anterior, confirmando o que nela foi dito.

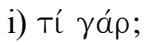

Embora tenha forma interrogativa, esta fórmula tende a reafirmar o que foi dito anteriormente, como que considerando impossível qualquer outra possibilidade. A tradução varia no verbo que deverá ser escolhido em função do contexto, mas, de uma forma geral, será “o que mais poderia [verbo]?”:

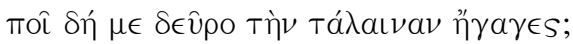

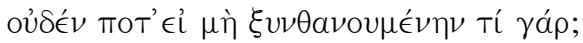

Ah, para que me trazes aqui, sendo eu uma desgraçada?

Para outra coisa não é senão para morrer. O que mais poderia ser?

(A.A.1135-1136)

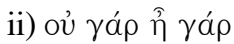

Representa(m) um pedido de confirmação no modo interrogativo formulado através da negação da proposição anterior, cuja tradução mais indicada será “não é assim?”. É usado principalmente por Platão, na medida em que constitui uma arma preferencial de Sócrates para levar a cabo as suas argumentações:

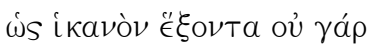

Porque isso trar-lhe-ia graves consequências. Não é assim?

(Pl.Grg.480a.2) 
3. Formulação de um desejo

Além dos usos e sentidos puramente semânticos que foram anteriormente referidos, esta partícula pode entrar numa construção de teor sintáctico, embora, ao contrário do que possa parecer, não desempenhe qualquer papel a esse nível. Limita-se a acompanhar a conjunção $\epsilon i$ reforçando o seu sentido inerentemente condicional. O desejo mais não é do que uma condição em cuja realização o interlocutor focaliza o seu interesse e não será por acaso que a sua formulação consiste na articulação entre a conjunção usada nas orações condicionais $(\epsilon i)$ e uma partícula que tende a focalizar um determinado aspecto, fazendo a passagem do geral para o particular. Mas, visto que a formulação do desejo pertence a outro campo de análise, fica apenas a remissão para bibliografia mais adequada ${ }^{6}$.

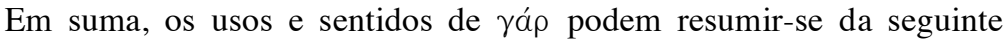
forma: em estruturas de subordinação directa, a partícula pode assumir os sentidos explicativo/completivo e causal, pode justificar um vocativo e introduzir uma expressão parentética; em estruturas de subordinação indirecta, pode equivaler a assentimento e formar interrogações elípticas com sentido confirmativo. Finalmente, pode entrar na formulação do desejo como reforço da conjunção $\epsilon i$.

Quanto à sua colocação, só não inicia uma frase, podendo ocupar qualquer uma das outras posições, o que, por vezes, permitia aos poetas resolver alguns problemas relacionados com a métrica.

RODOLFO PAIS NUNES LOPES

6 W. Goodwin, Greek Grammar, London, Macmillan, 1979, §§1507, 1511, $1512,1537,1610$. 